\title{
Digital Health in Cardiology: The Estonian Perspective
}

\author{
Eno-Martin Lotman ${ }^{a} \quad$ Margus Viigimaa $^{b}$

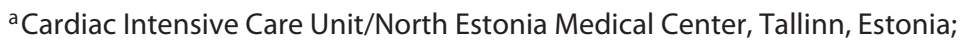 \\ ${ }^{b}$ North Estonia Medical Center, Tallinn University of Technology, Tallinn, Estonia
}

\section{Keywords}

Digital cardiology · Digital health · eHealth · e-Estonia

\begin{abstract}
Background: Digital health is rapidly entering clinical practice in cardiology. Estonia is one of the leading nations in implementing digital nationwide solutions. Recently, the European Society of Cardiology organized the 1st Summit on Digital Health in Tallinn, which provided the opportunity to discuss various aspects concerning the digitalization of cardiology. Summary: The current review focuses on the advancements of Estonian digital health and digital cardiology as well as possible barriers and solutions for implementing digital innovations in cardiology. Key Messages: The authors have included aspects from the recent summit, personal communications, and literature reviews to express the current state and future possibilities of digital health in cardiology from the Estonian perspective.
\end{abstract}

(c) 2019 S. Karger AG, Basel

\section{Introduction}

Cardiology is inherently connected to high-tech and digital innovations due to its close associations with interventions, computation, and imaging. As defined by the World Health Organization, eHealth is "the use of infor-

\section{KARGER}

๑) 2019 S. Karger AG, Basel

E-Mail karger@karger.com

www.karger.com/crd mation and communications technology in support of health and health-related fields." Mobile health (mHealth) is a subset of eHealth and is defined as "the use of mobile wireless technologies for health." The term digital health is defined as "a broad umbrella term encompassing eHealth (which includes mHealth), as well as emerging areas, such as the use of advanced computing sciences in big data, genomics and artificial intelligence" [1].

Ideally, platforms that integrate digital health should synergize the health care system participants - patients, health care providers, researchers, pharmaceutical and medical technology companies, and mobile application developers. In order to achieve this, the digital health platforms can include various tools, including technologies that utilize digital, mobile, and cloud-based platforms, telemedicine and telecare communications, health information technology, wearable devices, chatbots, artificial intelligence, genomics, and personalized medicine.

\section{Recent eHealth Congresses in Estonia}

Recently, the European Society of Cardiology (ESC) e-Cardiology Working Group developed a position paper on the challenges in digital health implementation in cardiovascular medicine that relates to the ESC action plan to play a proactive role in all aspects of the eHealth agen-

\footnotetext{
Margus Viigimaa

North Estonia Medical Center, Tallinn University of Technology

J. Sütiste tee 19

EE-13419 Tallinn (Estonia)

E-Mail margus.viigimaa@ regionaalhaigla.ee
} 
da in the support of cardiovascular health in Europe and beyond. Also, recently, the World Health Organization developed its own recommendations on the strengthening of health systems with digital interventions. In view of this, we hereby present a brief overview of the Estonian perspective of digital health in cardiology.

Recently, Estonia has hosted a number of international conferences related to digital health. In September 2019, the Tallinn Digital Summit took place, which covered health care among other topics. The main focus of these sessions was the idea that artificial intelligence along with other breakthrough technologies, such as blockchain, Internet of Things, sensors, and virtual reality, can enable significant advances in health care by improving patient outcomes and efficiency of health care systems, but questions remain on how to ensure protection of patient privacy.

More specifically, Estonia hosted the 1st ESC Summit on Digital Health. The comprehensive program included interactive discussions, roundtables, sessions, and workshops, with various interest groups presenting their view of the future of digital health in cardiology. Among others, a number of industry specialists, experts on digital health, health care professionals, patients, policy makers, and financiers took their stand. Topics covered by the Summit focused on the opportunities and hurdles that lie ahead in the road to digital health implementation in cardiology. With this 1st Summit, the ESC positioned itself at the forefront of digital health.

The summit in Tallinn was all about digital innovations, and one of the key sessions included expert panel discussions about the development of interoperable digital health ecosystems. Estonia's Piret Hirv presented the business side of the story: Estonia has a greatly resourceful nationwide health information system, but it still lacks value-adding consumer-friendly services, which would connect the person to the system. In the medical field, the whole ecosystem needs to support businesses in implementing services, which is the reason behind creating the Estonian Connected Health Cluster that connects all stakeholders - public and private persons, and patients.

Erkki Leego, the Chief Digital Officer at the University of Tartu, pointed out that after more than 2 decades of digital developments in Estonia, the young health care professionals expect to have modern user-friendly eHealth services at the hospital level, e-prescriptions, etc. This leads to both very high expectations and also trust in the system by the general population, which is something many countries do not have. The trust is based on data use logging and long-term use without any incidents of data misuse. Kalle Killar, the Deputy Secretary General on e-Services Development and Innovation at the Ministry of Social Affairs (MSA) reflected also on the high trust and expectation for the digital health ecosystem. These expectations have led to next-level issues. For example, the clinical data that have been collected already are not intended to be used with genomic data in everyday clinical practice, and now we need to start collecting data to be able to solve future problems, and the hope is that an ongoing personalized medicine initiative will take the overall quality of the eHealth system to the next level. It was generally agreed that in order to reach the next level in eHealth, it is important to find an appropriate model of cooperation between the public sector, health care providers, companies, and universities.

\section{Estonian National Policies}

Estonia is an innovative nation in Northern Europe known for its digital achievements and ambitions. Thanks to nationwide e-solutions, it is possible to start a company within few hours and to declare taxes in minutes. Estonia is a world leader on e-governance and cybersecurity. This country consistently ranks among the top of Internet freedom [2]. Estonia has also developed unique digital health innovations, including nationwide digital prescriptions and an eHealth system that integrates data from Estonian health care providers to create a medical history that every patient and health care provider can access online. The national electronic ID card system and blockchain technology are used to ensure that health data are secure. Estonia's solution for the future of health care - Healthcare 4.0 - utilizes personalized medicine and genome-based analysis for individuals to participate more actively in their health care and have better access to their information [3].

\section{A Growing Part of Health Economy}

It is generally acknowledged that digital health services are growing rapidly due to several factors. The global digital health market is valued at USD 85-100 billion and is projected to grow rapidly in the coming years [4]. The leading factors for the growth of the sector are:

1. Improved overall digital services and better wireless connections [5].

2. Improved tech savviness in all age groups, including the elderly [6].
Lotman/Viigimaa 
Table 1. Local perspective: list of samples of Estonian start-ups active in different cardiovascular disease settings

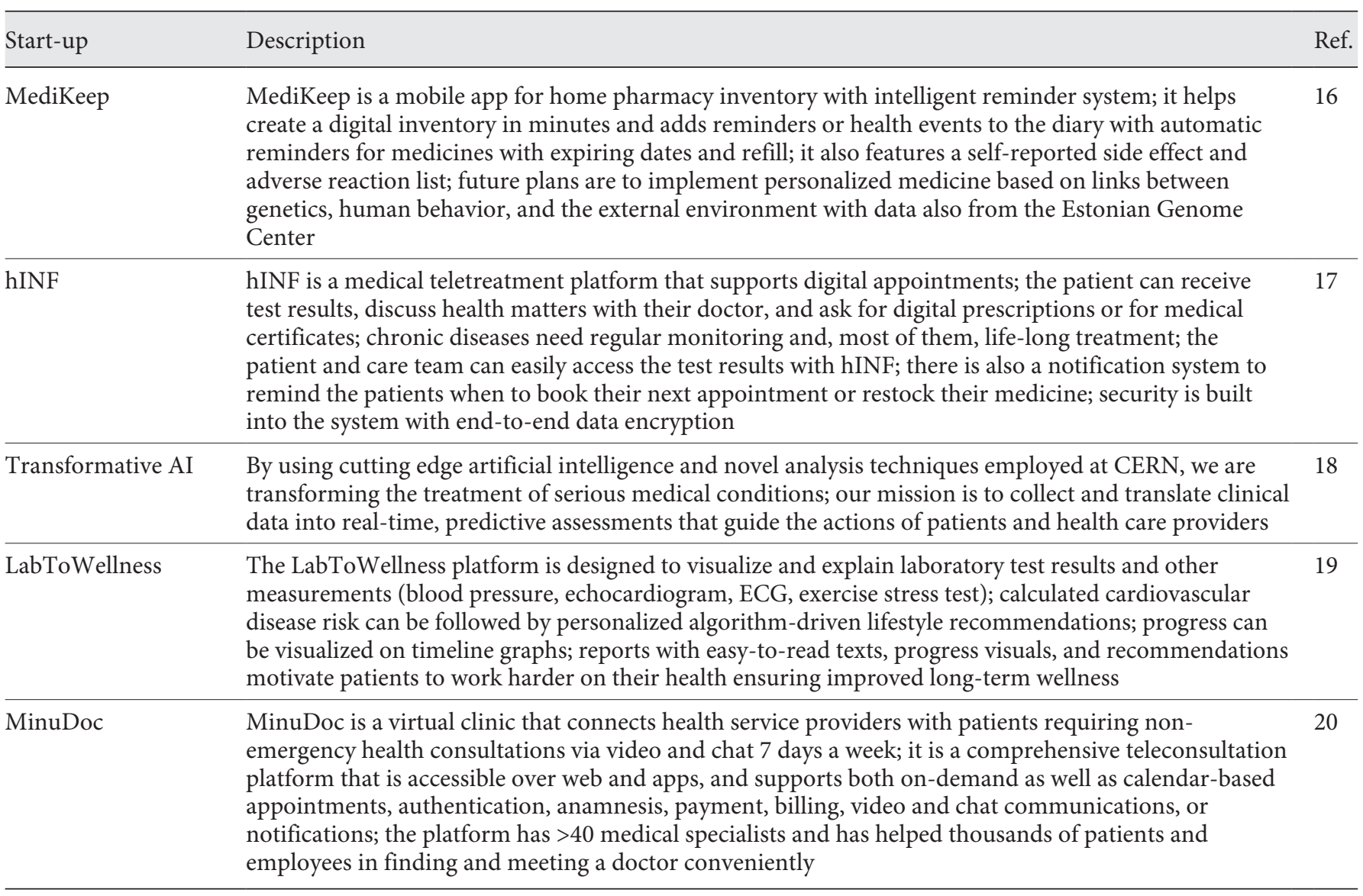

3. Increased life expectancy and increased prevalence of chronic noncommunicable diseases, especially in people of lower socioeconomic status [7].

4. Increased demand by health care stakeholders for shared health and outcome data from patients, insurers, and health care service providers.

5. Rising health care costs and the potential for digital health services for reducing the costs.

6. Disparities of health care workforce and the need for improving access to health care for rural communities.

7. Increasing corporate interest in investing in digital health solutions.

These factors are gaining momentum also in Estonia. The overall adoption and availability of digital services in Estonia is on the rise. Estonia ranks 8th in the European Union in the Digital Economy and Society Index [8] (DESI) (a composite index that summarizes relevant indicators on Europe's digital performance and tracks the evolution of EU member states in digital competitiveness). In addition, life expectancy has increased in Estonia by more than 10\% during the 21st century according to Statistics Estonia [9]. The rise in life expectancy has contributed to the rise in health care expenditures, with the total health expenditure per capita rising from EUR 486.20 in 2000 to EUR 1,885.2 in 2015 [10]. There are also significant disparities in access to health care in Estonia. According to a 2018 European Social Policy Network report, the overall self-reported unmet needs for medical care due to costs, travel distance, and waiting time in 2016 was $15.3 \%$ [11], which made Estonia ranking highest on this indicator in the EU. Therefore, Estonia has both the possibilities for implementation and a significant unmet need, which could be at least in part solved with digital health care solutions.

\section{Reimbursement for Implementation}

The Estonian health care system is predominantly funded by solidarity-based mandatory health insurance contributions in the form of a social payroll tax, which 
accounts for about two-thirds of total health care expenditure. The MSA provides direct financing of emergency care for uninsured people and public health programs. Private expenditure consists mostly of co-payments for medicines and dental care. The main purchaser of health care services for insured people is the Estonian Health Insurance Fund (EHIF) [12]. The health insurance system covers about $94 \%$ of the population [10].

According to the Estonian eHealth strategic development plan, the country's eHealth strategy is funded by various parties, including the budget of the MSA and EHIF. More specifically, the expenses of the health care providers receive reimbursement for the provision of eHealth services (e.g., the procurement and licensing of software and hardware necessary for the provision of services or archiving of documents in the health information system). Moreover, there are also plans for the inclusion of information and communications technology components of the health care service prices to be linked with the quality requirements for the provision of health care services. This would ideally facilitate the development of necessary information systems by health care service providers [13].

The issue of reimbursement for digital health applications has been thoroughly discussed, as it presents a major hurdle for implementations and also protects from innovations that might not provide the expected results. The Estonian reimbursement model is still work in progress. The EHIF assessment and financing framework for digital health was also presented at the ESC Summit on Digital Health, and according to this, it will be possible to provide reimbursement for models that provide value to accelerate uptake and also an innovation fund for potential models that could provide value but need more evidence.

Reimbursement is also a substantial issue for newcomers to the digital health business model, as much of the costs of health care are provided through reimbursement from insurers. There are several start-ups (Table 1) that are actively developing their solutions in Estonia, some of which have included public reimbursement plans in their business model.

\section{Computerized Decision Support Systems}

A clinical decision support system (CDSS) is an active system used to generate case-specific recommendations to improve clinical outcomes, avoid adverse effects, and improve efficiency.

An Estonian systematic review of various available CDSSs for the treatment of cardiovascular conditions demonstrated that computer-based CDSSs improved prespecified clinical outcomes. It was observed in the studies that these programs improve monitoring of treatment (number of blood pressure measurements), prescription of medicinal products according to treatment guidelines, and utilization of health care resources, and decrease rates of rehospitalizations [14].

A feasibility study demonstrated that the data in the Estonian Health Information System (EHIS), EHIF, and Estonian Genome Center of the University of Tartu (EGCUT) databases are available for the large-scale deployment of CDSSs. Although it was found that some of the data are stored in a structured format, a considerable amount of data is stored either as a narrative text or in noncompliant structures, which are a challenge to the development of a nationwide CDSSs [15]. As a result of these and many other analyses, a procurement was initiated by the EHIF to initiate a nationwide CDSS for primary care. The results of its implementation in Estonia are to be seen in the near future.

\section{Inter-Provider e-Consultations}

Cooperation between primary care physicians and cardiologists is crucial for providing seamless cardiovascular high-quality medical care, and e-consultations form an integral part of developing digital health care. To improve this cooperation, an e-consultation service has been active in Estonia since 2013. This service enables family physicians to quickly and conveniently consult a specialist electronically via the secure Health Information System. The system has been gaining user base quickly, and from 2017 to 2018, the number of responses received from the e-consultations increased by half. The patients can also review the e-consultations related to their health record in the patient portal [12]. These consultations are especially important for rural areas, thus addressing the unmet need experienced by these populations. There are also several start-ups in Estonia (Table 1) looking to solve the unmet need for patient-doctor consultations without the need for physical contact, as this can prove to be difficult in rural areas.

\section{Barriers and Solutions to Patients with Cardiovascular Diseases}

There are several reported factors that may present as barriers to implementation of digital health solutions in patients with cardiovascular conditions. For example, it
Lotman/Viigimaa 
has been postulated that personal characteristics such as health status, lack of personal motivation, low acknowledged value of digital health services, low perception of the changing roles of patient and doctor, low education, and socioeconomic status may be the most important barriers for digital health adoption [21]. Environmental issues that could hinder the adoption of digital health solutions include concerns for privacy, security, and quality; accessibility to digital resources; overall digital literacy in society; or financial well-being, for example. It has also been reported that concerns about receiving a poorer level of care due to the impersonal nature of digital services could pose a problem [21].

All of the aforementioned barriers can have specific solutions. Estonia has been a front-runner in the advancement of digital literacy. Already in 1997, the Tiger Leap Foundation was launched, which was the first step in providing all schools with computers and internet access. This was followed by a second initiative focused on the students, teachers, and educational staff in 2001. The successor of these programs is the Information Technology Foundation for Education, which will continue with the improvement in public digital literacy. Concerns for privacy and security can be overcome with openness and transparency. Citizens' trust in the digital state and services and a basic societal understanding of the importance of cybersecurity are high in Estonia, but being one of the world's most digitally dependent countries, the potential impact of cyber threats are significantly increased [22].

\section{Barriers and Solutions to Providers of Cardiovascular Care}

The clinical endorsement by physicians and other health care providers is of high importance, both because of the potentially lost users and also because the lack of it may become a barrier for wider adoption if patients feel that their doctors do not want to use these services themselves [21]. The endorsement by health care providers may be hindered by the perception of data overload and need for exceeding time investments to review digital health-related data and provide feedback to the patients [21]. The increasing use of email or other Internet communications with a doctor, patients tracking personal health information, including diet, weight, and physical activity, for example, can pose a serious threat to the busy cardiologist if presented during an outpatient visit from the expecting patient's smartphone.

Implementing Digital Innovations in Cardiology in Estonia
One of the solutions for the threat of data overload would be avoiding the addition of digital health care on top of existing care [21]. The delivery of care in this situation would, for example, decrease the outpatient visit times and substitute these with digital encounters, thus blending the digital care with the existing model. This would also allow for easier daily and increasingly continuous patient monitoring and digital feedback by chatbots, for example, rather than approaches involving prespecified outpatient visits to clinical personnel.

A good example of this is the remote monitoring of cardiac implantable electronic devices. Its integration with clinical visits could improve outcome. The remote monitoring of implantable cardioverter defibrillators and cardiac resynchronization therapy (CRT) devices has been implemented with success in Estonia. According to the ESC CRT Survey II, 72.4\% of CRT devices were monitored by telemetry in 2016, which ranked higher than average in the ESC members [23]. Remote monitoring of cardiac implantable electronic devices is currently not reimbursed in Estonia, which is also the case in most other European implanting centers [24], although improved outcomes compared with outpatient visits alone and cost-effectiveness of remote monitoring have been reported [25].

Digital solutions could also be of help to physicians collecting the medical history of cardiovascular patients. Parts of medical history, including diet, weight, and physical activity, and use of medications, for example, could be collected online beforehand by wearable devices. These wearables include smart watches, wristbands, subcutaneous sensors equipped with gyroscopes, accelerometers, optical sensors, cameras, temperature sensors, and many more, which are capable of monitoring a range of data points from medical history. This poses a challenge, as interpreting data from various sources and different classifications could be difficult. Algorithm-based or artificial intelligence-based data mining could provide a solution, but these solutions are still in infancy and confined to medical research. Some of the start-ups that are active in Estonia are also looking to improve data processing and risk assessments based on large data volumes collected by the health care providers (Table 1).

\section{Conclusions}

Digital health innovations support contemporary cardiovascular health care delivery. In the near future, they could help to facilitate a more personalized health care, 
and improve quality and participant experience. Estonia has been in the frontlines of digital developments with the help of governmental initiatives and solutions combined with the possibilities generated by a high digital literacy and digital innovations from the private sector. Estonia is determined to contribute significantly to the developments of cardiovascular digital health.

\section{Statement of Ethics}

Ethical approval was not required for this study.

\section{Disclosure Statement}

Dr. Lotman discloses consultancy to the following digital health care companies: Health-Circle OÜ and Transformative AI OÜ. Prof. Viigimaa discloses consultancy to the HealthBook OÜ and Amgen Inc.

\section{Funding Sources}

The authors report no funding for this review.

\section{Author Contributions}

Dr. Lotman: data aggregation, text compilation, and text refinement.

Prof. Viigimaa: text compilation and text refinement.

\section{References}

1 WHO guideline: Recommendations on digital interventions for health system strengthening. Geneva: World Health Organization; 2019. Licence: CC BY-NC-SA 3.0 IGO.

2 Freedom on the net 2018 report. Available from: https://freedomhouse.org.

3 e-estonia. Available from: https://www.eestonia.com.

4 Coherent Market Insights. 2018 Jul. Available from: https://www.coherentmarketinsights. $\mathrm{com} /$.

5 OECD. Enhancing Access and Connectivity to Harness Digital Transformation, OECD Going Digital Policy Note. Paris: OECD; 2019. Available from: www.oecd.org/going-digital/ enhancing-access-digital-transformation.pdf.

6 Smith A. Older adults and technology use. Washington, DC: Pew Research Center; 2014. Available from: http://www.pewinternet. org/2014/04/03/older-adults-and-technologyuse/.

7 Marmot M, Bell R. Social determinants and non-communicable diseases: Time for integrated action. BMJ. 2019 Jan;364:1251.

8 The Digital Economy and Society Index (DESI). Available from: https://ec.europa.eu/ digital-single-market/en/desi.

9 Statistics Estonia. Available from: https:// www.stat.ee/news-release-2018-094.

10 Habicht T, Reinap M, Kasekamp K, Sikkut R, Aaben L, van Ginneken E. Estonia: health system review. Health Syst Transit. 2018 Mar: 20(1):1-189.
11 Baeten R, Spasova S, Vanhercke B, Coster S. Inequalities in access to healthcare. A study of national policies, European Social Policy Network (ESPN), Brussels: European Commission; 2018.

12 Estonian Health Insurance Fund. Available from: https://www.haigekassa.ee/en.

13 Estonian eHealth Strategic Development Plan 2020. Task Force operating within the Government Office from July 2014 to November 2015. Available from: http://etervis2025.sm. ee/.

14 Ross P, Läänelaid S, Vanker E, Pruks I, Viigimaa M, Padrik P, et al. Feasibility study for the development of digital decision support systems for personalised medicine. Tallinn University of Technology, 2015. Available from: https://www.sm.ee/et.

15 Kalda R, Kathiresan S, Kiivet RA, Lotman EM, Padrik P, Reppo I, et al. Feasibility Study for Personalised Medicine in Estonia: Clinical Approach. Tartu University, 2015. Available from: https://www.sm.ee/et.

16 Personal communication and provider information. Available from: https://medikeep. $\mathrm{eu} /$.

17 Personal communication and provider information. Available from: https://hinf.eu/.

18 Personal communication and provider information. Available from: http://transformative.ai.

19 Personal communication and provider information. Available from: https://www. labtowellness.com.

20 Personal communication and provider information. Available from: https://www. minudoc.ee/.
21 Frederix I, Caiani EG, Dendale P, Anker S, Bax J, Böhm A, et al. ESC e-Cardiology Working Group Position Paper: overcoming challenges in digital health implementation in cardiovascular medicine. Eur J Prev Cardiol. 2019 Jul;26(11):1166-77.

22 Ministry of Economic Affairs and Communications. Cybersecurity Strategy. Republic of Estonia. 2019-2022. Available from: https://www.mkm.ee/sites/default/files/ kyberturvalisuse_strateegia_2022_eng.pdf.

23 Dickstein K, Normand C, Auricchio A, Bogale N, Cleland JG, Gitt AK, et al. CRT Survey II: a European Society of Cardiology survey of cardiac resynchronisation therapy in 11088 patients-who is doing what to whom and how? Eur J Heart Fail. 2018 Jun;20(6):1039_ 51.

24 Mairesse GH, Braunschweig F, Klersy K, Cowie MR, Leyva F. Implementation and reimbursement of remote monitoring for cardiac implantable electronic devices in Europe: a survey from the health economics committee of the European Heart Rhythm Association. Europace. 2015 May;17(5):814-8.

25 Costa V, Yeung MW, Gilbert J, Holubowich C; Health Quality Ontario. Remote Monitoring of Implantable Cardioverter-Defibrillators, Cardiac Resynchronization Therapy and Permanent Pacemakers: A Health Technology Assessment. Ont Health Technol Assess Ser. 2018 Oct;18(7):1-199. 